\title{
Universal Design for Learning and Instruction: Perspectives of Students with Disabilities in Higher Education
}

\author{
R. David Black, Lois A. Weinberg, Martin G. Brodwin \\ California State University, Los Angeles
}

\begin{abstract}
Universal design in education is a framework of instruction that aims to be inclusive of different learning preferences and learners, and helps to reduce barriers for students with disabilities. The principles of Universal Design for Learning (UDL) and Universal Design for Instruction (UDI) were used as the framework for this study. The purposes of this study were to evaluate the perspectives of university students with disabilities on teaching methods and strategies conducive to their learning, and to evaluate how their perspectives align with UDL/UDI. The findings of this study revealed that there are barriers to learning for students with disabilities. Students with and without disabilities reported having a variety of learning preferences, and rated UDL/UDI principles as useful in improving their learning. The students gave several perspectives that supported the principles of universal design in higher education to enhance the learning of students who have disabilities.
\end{abstract}

To implement Universal Design for Learning and Universal Design for Instruction (UDL/UDI), it is necessary to develop an understanding of whether the needs of students are being met in higher education. The purposes of this study were to evaluate the perspectives of university students with disabilities on teaching methods and strategies conducive to their learning, and to evaluate how their perspectives align with UDL/UDI. The study was developed to understand how UDL/UDI might create a more inclusive environment for students with disabilities (physical or mental impairment that substantially limits one or more major life activities) in higher education by learning about the perspectives that students with disabilities have on the accommodation process, 
learning experience, and teaching methods. Students without disabilities were also included in the study to gain a sense of their learning preferences, their learning experiences, and their views on UDL/UDI.

Individuals with disabilities who attend institutions of higher education (IHEs) continue to experience barriers to learning. These barriers may include: (a) students with visual disabilities not receiving materials in a format that is accessible; (b) students who are Deaf exposed to lectures that require hearing; (c) students who use wheelchairs not having classrooms in accessible locations; (d) students with autism and fine gross motor challenges having to take impromptu exams or do handwritten activities; and (e) students with learning disabilities (LD) not receiving accommodations that enable them to demonstrate what they know (Block, Loewen, \& Kroeger, 2006; Burgstahler, 2007; Burgstahler \& Moore, 2009; Marshak, Van Wieren, Ferrell, Swiss, \& Dugan, 2010). There are also other types of barriers unintentionally created by IHEs, such as accommodations that are inappropriate or delays in creating alternate format textbooks.

Accommodation is defined in the United States as "reasonable accommodation" under the Americans with Disabilities Act (1990). As it applies to education, accommodation refers to making existing facilities readily accessible to and usable by individuals with disabilities. This encompasses acquisition or modification of equipment or devices; appropriate adjustment of or modifications to examinations, training materials, or policies; provision of qualified readers or interpreters; and similar accommodations for individuals with disabilities. While accommodations can be used to address some of the needs of students with disabilities, they may include extra steps and barriers created in the accommodation process. This is because accommodations typically are developed after the design of the instructional setting, curriculum, and teaching methods. If classroom, curriculum, teaching methods, and university procedures were developed with those considerations and accommodations built in, then many of these barriers might be alleviated. This is what Universal Design (UD) in education purports to do (Burgstahler, 2007). Another issue with accommodations is that educators, such as disability service providers, often assign accommodations for students without considering whether they are most appropriate and helpful for the student (Hehir, 2005).

The idea behind UD is access for all individuals (Embry, Parker, McGuire, \& Scott, 2005). The original concept involved architectural design. There are seven original UD principles, as summarized in Table 1 (Center for Universal Design, 1997, 2008). UD in learning and instruction involves various approaches, such as presenting material in multiple formats, so that students with different abilities and backgroundsincluding students with English as a second language, students from multicultural backgrounds, and students with disabilities - can access the educational material.

Several terms are used based on the universal design concept. Universal design for learning (UDL) is curriculum that emphasizes the need for flexibility and encourages faculty to consider a framework for designing courses that provide multiple means of representation, expression, and engagement (CAST, 2013b; Pliner \& Johnson, 2004; also see Table 1). Representation includes different ways of presenting instructional 
material so that the greatest number of students can access the material flexibly in a way that meets their needs, since learners differ in how they understand and perceive information. Thus, it is important to have multiple ways of presenting information from which learners can choose, such as use of lectures, guest speakers, web pages, or activities. Expression includes students demonstrating what they learn through different types of assessment, including exams, papers, or projects. Engagement encompasses different modes for student involvement, such as use of classroom interactive activities, discussions, or online chat rooms. UDL has been developed for the $\mathrm{K}-12$ setting; however, advocates propose that the principles of UDL have potential applications in higher education as well (Ashman, 2010; Rose, Harbour, Daley, \& Abarbanell, 2006).

Universal design for instruction (UDI) is an approach to teaching that uses proactive design and inclusive instructional strategies to benefit a broad range of learners in higher education (McGuire, Scott, \& Shaw, 2006). UDI focuses on enhancing student learning through the application of UD principles to the instructional design process (McGuire et al., 2006; University of Guelph, 2011). The principles of UDI apply the original seven UD principles to instruction in the education setting. Two principles are added to the original UD principles, including "community of learners" and "instructional climate" (Burgstahler, 2012; McGuire \& Scott, 2006b; McGuire, Scott, \& Shaw, 2003). These same UDI principles are also found in UDL guidelines, multiple means of representation (see Table 1).

UDL and UDI are similar in their concepts (see Table 1), but they are also distinct in their focus. UDI is based on the original UD principles by Mace (1985) and focuses on environment and accessibility. Primarily applied in the postsecondary education setting, it involves approaches to instruction allowing students of different backgrounds to benefit (Center for Universal Design, 2008). UDL focuses on the learner and is based on neuroscience and neurocognitive fields. Originally implemented in middle-schools, it has been expanding to other levels, such as higher education (CAST, 2013a).

When IHEs provide accommodations for students with disabilities after the curriculum and instructional methods have already been designed, they are not always appropriate to the students' functional needs and may only include a set menu of accommodations. For example, a student with low vision may be given the accommodation of a closed-caption television (CCTV). However, after longer periods of use, CCTV may cause eye strain and impede learning; a screen reader or combination of using both CCTV and screen reader may have been more effective. In another example, a student who is hard of hearing may receive accommodation in the form of a frequency modulation (FM) hearing aid. It increases both volume and background noise, making it difficult to concentrate. Therefore, the student's learning needs may be inadequately addressed (Burgstahler, 2007; Kurth \& Mellard, 2006; Marshak et al., 2010). 


\section{Table 1}

Comparison of the Principles of Universal Design, Universal Design for Learning, and Universal Design for Instruction

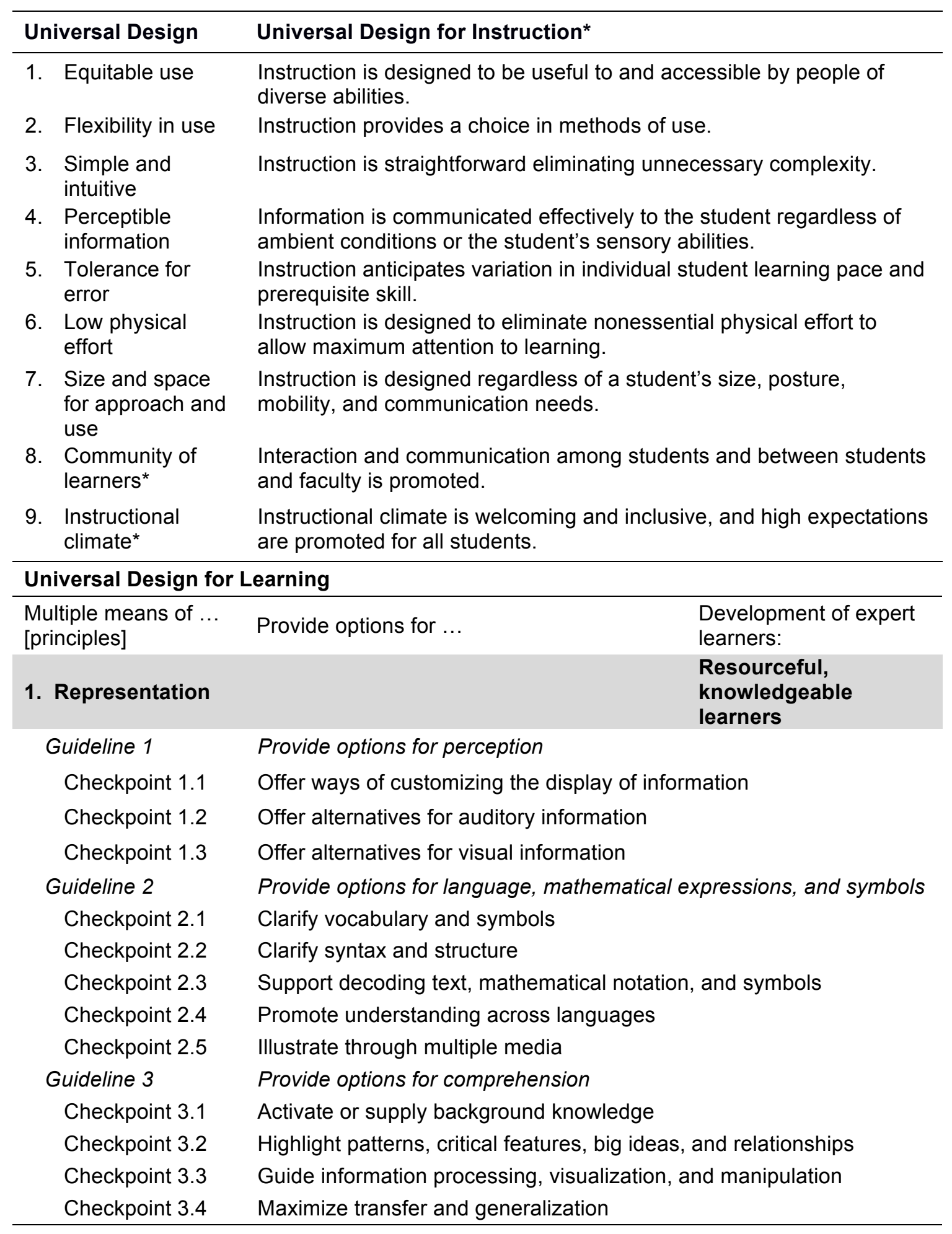


Table 1 cont'd...

\begin{tabular}{|c|c|}
\hline 2. Expression & $\begin{array}{l}\text { Strategic, goal- } \\
\text { directed learners }\end{array}$ \\
\hline Guideline 4 & Provide option for physical action \\
\hline Checkpoint 4.1 & $\begin{array}{l}\text { Vary the methods for response and } \\
\text { navigation }\end{array}$ \\
\hline Checkpoint 4.2 & Optimize access to tools and assistive technologies \\
\hline Guideline 5 & Provide options for expression and communication \\
\hline Checkpoint 5.1 & Use multiple media for communication \\
\hline Checkpoint 5.2 & Use multiple tools for construction and composition \\
\hline Checkpoint 5.3 & $\begin{array}{l}\text { Build fluencies with graduated levels of support for practice and } \\
\text { performance }\end{array}$ \\
\hline Guideline 6 & Provide options for executive functions \\
\hline Checkpoint 6.1 & Guide appropriate goal-setting \\
\hline Checkpoint 6.2 & Support planning and strategy development \\
\hline Checkpoint 6.3 & $\begin{array}{l}\text { Facilitate managing information and } \\
\text { resources }\end{array}$ \\
\hline Checkpoint 6.3 & Enhance capacity for monitoring progress \\
\hline 3. Engagement & $\begin{array}{l}\text { Purposeful, motivated } \\
\text { learners }\end{array}$ \\
\hline Guideline 7 & Provide options for recruiting interest \\
\hline Checkpoint 7.1 & Optimize individual choice and autonomy \\
\hline Checkpoint 7.2 & Optimize relevance, value, and authenticity \\
\hline Checkpoint 7.3 & Minimize threats and distractions \\
\hline Guideline 8 & Provide options for sustaining effort and persistence \\
\hline Checkpoint 8.1 & Heighten salience of goals and objectives \\
\hline Checkpoint 8.2 & Vary demands and resources to optimize challenge \\
\hline Checkpoint 8.3 & Foster collaboration and communication \\
\hline Checkpoint 8.4 & Increase mastery-oriented feedback \\
\hline Guideline 9 & Provide options for self-regulation \\
\hline Checkpoint 9.1 & Promote expectations and beliefs that optimize motivation \\
\hline Checkpoint 9.2 & $\begin{array}{l}\text { Facilitate personal coping skills and } \\
\text { strategies }\end{array}$ \\
\hline Checkpoint 9.3 & Develop self-assessment and reflection \\
\hline
\end{tabular}

In contrast, UDL/UDI incorporates various modalities to learning and best teaching strategies to enhance learning (CAST, 2013b; Madaus, Scott, \& McGuire, 2003a). UDL/UDI involves basing curriculum on a student's individual learning preferences and providing an environment that is flexible, in order to support learner variability and to enhance learning and engagement, rather than just teaching a subject. Another important factor to consider is not just accessibility but also usability (Bevan, 1995; Sapp, 2007). These terms are not always interchangeable. For example, an individual with a disability may be able to access items on a web page, but may not be able to use them efficiently. Usable means that an individual can use the instructional materials or websites efficiently, effectively, and with satisfaction (Bevan, 1995). 
Properly applied, UDI/UDL principles should help students be self-motivated and successful in higher education. To explore the success of UDI/UDL, in this study we sought to gain an understanding of the perspectives of students with disabilities on their needs and of the current issues they face in higher education. The research questions for this study were: (a) What perspectives do students with and without disabilities have of faculty instructional methods and strategies that are conducive to their learning? (b) How do their perspectives of these instructional methods align with the principles of UDL/UDI?

\section{Method}

\section{Study Design}

This primarily qualitative study employed a phenomenological approach. This approach was chosen since students experienced a common phenomenon-classroom instruction (Creswell, 2012). The goal was to describe the students' understandings in as much detail as possible. A qualitative approach was chosen to explore whether student perspectives aligned with UDL/UDI, but also whether there are other needs or concerns students may have beyond the scope of UDL/UDI. Interviews of students with and without disabilities took place during November and December of 2011 at an IHE.

\section{Description of Community-Based Setting}

The community setting for this study was an urban four-year university in southern California. Of the 21,284 students at the university, 82\% were undergraduates and 59\% were female. The number of students with disabilities registered at the Office for Students with Disabilities (OSD) was 671 (3.2\%). Students are able to receive support from OSD following an initial intake appointment, during which disability-related documentation is provided and students discuss their needs and request accommodations. If no documentation is provided, or there is suspicion of a disability that has not been diagnosed, such as LD, students are referred for testing and evaluation. Students are then provided a "provision for accommodation letter," which they can use to submit requests to faculty for accommodations prior to or at the beginning of each course. The OSD generally provides the accommodations. A list of accommodations offered shows the most common are: alternate format textbooks, test proctoring for students needing extra time for exams, note taking, tape or digital recorders, American Sign Language interpreters, telecaptioning, use of screen readers, and other assistive software on campus or for exams. Implementation of UD principles is still in the initial phases, mainly in development and creating awareness on campus.

\section{Ethics, Access to the Site, and Role as Researchers}

The university's Institutional Review Board approved the study. Entry into the study site for the purpose of obtaining access to students with disabilities had been established through a collaborative relationship and internship at the OSD by the first author. The first author was a student in the Educational Leadership doctoral program at the 
university and had a dual role as investigator and insider. The second and third authors are professors at the university. All information about students was kept confidential to ensure limits on risk, and participation was voluntary with students understanding that they could withdraw from the study at any time.

\section{Recruitment and Selection of Participants}

Recruitment of students with disabilities was through the OSD by word of mouth, through a general email to all students with disabilities registered at OSD (emailed twice during the study period), and with a flyer posted in the OSD. Students without disabilities were recruited through flyers posted on the physical campus, and through word of mouth. Recruitment was ongoing for three months during the study period. For phenomenological studies, Creswell (2012) recommended three to ten participants. The aim for this study was 12 students with disabilities and 3 without disabilities, from either undergraduate or graduate levels. Researchers have recommended for phenomenological studies, that 5 to 25 participants be interviewed (Creswell, 2012). The goal of 15 students was adopted, since it is the median between 5 and 25 , and since this number would provide enough information without being overwhelming to the researchers. Students with LD (with or without cognitive impairment) make up the largest proportion of students with disabilities at the university; thus, the aim for recruitment was at least 4 students with LD, and at least 2 students from each of the other disability types (sensory, psychiatric, and mobility impairment).

\section{Data Collection Procedures}

To capture student perspectives, an interview protocol and questions were developed (see Appendix A for the interview questions). Students all received the same questions in the structured interview. The interviews were conducted in person for 30 to 45 minutes on the school campus during times that were convenient to the student participants, such as between or after classes. Interviews were conducted privately in a small conference room located in a central location on campus. Interview questions provided both qualitative and quantitative data, since some questions included a Likert scale.

\section{Development of Interview Questions and Protocols}

The interview questions were designed to assess student perceptions on UDL/UDI by asking about the students' learning needs and whether they were being met; their engagement with the class, materials, and other students; feedback from professors; classroom experiences; and the process for obtaining accommodations (for students with disabilities). The protocol questions were validated prior to implementation of the study. A qualitative method for validating the questions using the "think aloud" approach described in the literature was used, where university students (not included in the study) read each question and gave feedback as to what they thought each question meant and why they answered items the way they did (Cohen \& Swerdlik, 2005; Mullens \& Kasprzyk, 1996). This approach helps to adjust the wording of each question to elicit a response that would answer the intent of each question. Four students were used for the validation of the interview questions. 
The interview questions were based on existing protocols on UD and accommodations from prior studies (Izzo, Murray, \& Novak, 2008; Kurth \& Mellard, 2006). Additional questions were added based on the principles of UDL/UDI. To improve validity, a structured interview protocol was developed to allow for ease of analysis and to minimize variations in student responses. Interview questions were grouped by learning preferences, accommodations and learning tools, and UDL/UDI principles. Questions related to the usefulness of specific accommodations, learning tools, and instructional methods, as well as questions related to to the importance of specific UDL/UDI principles, were designed with a Likert scale from 1.0 to 3.0.

Each interview question relates to at least one UDI principle and one UDL principle. Appendix A lists the interview questions and the related principles. For example, asking students how they rated the usefulness of a tape or digital recorder relates to the UDI principle of equitable use, since some students cannot take handwritten notes due to a disability. Taping or digitally recording lectures also relates to the UDL principle of expression for similar reasons, as it may be a better format for some students' learning preferences. Additionally, recording lectures can make it possible for students, including those with LD, to break up the information so it is easier for them to process and learn. Another example is asking students to rate the following statement: "You have the option to turn in individual project components for feedback for later integration into a final project." This relates to the UDI principle of tolerance for error, since students have varying skills in writing or comprehension, and providing ongoing feedback is helpful so students know how to make adjustments that will help them improve their writing and conform to assignment requirements. This also relates to the UDL principle of engagement, guideline 9.2 (see Table 1), since it helps students learn to adapt and learn how to be successful on an emotional and personal level.

\section{Data Analysis}

Each interview was audio recorded and transcribed using speech-to-text software (Dragon Naturally Speaking Preferred, Version 10) and human transcription. Transcriptions of student interviews were coded using thematic and conventional content analysis. The interviews were systematically analyzed and information reduced into themes (Creswell, 2012). Coding and thematic analysis was conducted by the first author. Descriptive, topic, and then analytic coding to determine themes was done. Open coding was also performed to identify concepts that were then grouped into themes elicited by students. Initial themes were compared to themes found in the literature review (e.g., accommodation issues, barriers) and used to define first-order codes. Operational definitions were developed based on the initial coding. Interviews were re-evaluated line by line for relationships among themes, and continued until no further insight was provided by additional analysis. Themes that emerged were also evaluated for frequency, number of students, and by student group (e.g., disability or no disability, disability type) to determine patterns and overall themes.

For data obtained from Likert scale questions, the median was calculated for each item. No statistical treatments, however, were applied, since the intent of the study was to gain a better understanding of student perspectives. To improve reliability, one strategy 
was to use audio recording and verbatim transcription of the interviews to reliably capture the data. Another reliability measure was that a research assistant reviewed coding conducted by the first author to check for internal consistency and agreement between the transcripts of the interviews and the emergent themes. This also helped with inter-rater reliability.

\section{Results}

\section{Demographics}

Fifteen students were interviewed, twelve with disabilities and three without disabilities (Table 2). Eleven students were undergraduate level, and seven had their majors in the college of education (including counseling). There were five students with LD/cognitive disability, five with psychiatric disabilities (including anxiety disorder, post-traumatic stress disorder, schizophrenia, and attention deficit hyperactivity disorder), and two with visual impairment. Six students had more than one disability: Four had a mobility-related disability (impairment limiting use of arms or legs), one had a psychiatric disability, and one had LD. The median number of years students had been diagnosed with their disabilities was 13.5. One undergraduate and two graduate (one master's and one doctoral) students were without disabilities. Year-of-program was not collected.

\section{Overall Themes}

Themes that were consistent between students with $(n=12)$ and without disabilities $(n=3)$ included a desire for achievement, the importance of communication and feedback between student and professor or among students, connections of ability to relate the materials presented for class to learning accomplished by students, equality issues related to either access to class materials or how students are treated in class, support (from faculty and departments on campus), and reassurance that tools are available to help students achieve. Some themes were discussed by students with disabilities more often than by students without disabilities. These themes related to the importance of organizing the physical environment (11 students with disabilities and 2 without) to be conducive to learning, and equity issues related to how students are treated compared to students without disabilities ( 9 students with disabilities and 1 without). Other themes for students with disabilities were familiarity or lack of familiarity of faculty and staff in working with students with disabilities $(n=11)$, frustration with accommodations and school policies $(n=9)$, and stigma related to disabilities $(n=7)$ such as psychiatric or learning disabilities. Stress was another major theme. This related to additional concerns faced by students with disabilities but not by other students, such as having to rely on disability service staff to administer some accommodations, stress from extra time in studying $(n=6)$ or even transportation issues $(n=1)$. 
Table 2

Student Characteristics

\begin{tabular}{|c|c|c|c|c|c|c|}
\hline & $\begin{array}{c}\text { All } \\
n=15\end{array}$ & $\%$ & $\begin{array}{c}\text { With } \\
\text { Disability } \\
n=12\end{array}$ & $(\%)$ & $\begin{array}{c}\text { No } \\
\text { Disability } \\
n=3\end{array}$ & $(\%)$ \\
\hline Age in years (median) & $\begin{array}{c}33 \text { (range } \\
21-52 \text { ) }\end{array}$ & & $\begin{array}{l}34 \text { (range } \\
21-52 \text { ) }\end{array}$ & & $\begin{array}{l}30 \text { (range } \\
30-34)\end{array}$ & \\
\hline Male & 5 & (33.3) & 3 & $(25.0)$ & 2 & $(67.7)$ \\
\hline \multicolumn{7}{|l|}{ Status } \\
\hline Undergraduate & 11 & $(73.3)$ & 10 & $(83.3)$ & 1 & $(33.3)$ \\
\hline Graduate & 4 & $(26.7)$ & 2 & $(16.7)$ & 2 & $(67.7)$ \\
\hline \multicolumn{7}{|l|}{ College } \\
\hline Arts and Letters & 2 & $(13.3)$ & 2 & $(16.7)$ & 0 & $(0.0)$ \\
\hline $\begin{array}{l}\text { Education (including } \\
\text { Counseling) }\end{array}$ & 7 & $(46.7)$ & 5 & $(41.7)$ & 2 & $(66.7)$ \\
\hline Natural and Social Sciences & 2 & $(13.3)$ & 2 & $(16.7)$ & 0 & $(0.0)$ \\
\hline Business and Economics & 3 & $(20.0)$ & 2 & $(16.7)$ & 1 & $(33.3)$ \\
\hline Health and Human Services & 1 & $(6.7)$ & 1 & $(8.3)$ & 0 & $(0.0)$ \\
\hline \multicolumn{7}{|l|}{ Disability } \\
\hline Learning Disability (LD) & -- & & 4 & (33.3) & -- & \\
\hline Psychiatric & -- & & 6 & $(50.0)$ & -- & \\
\hline Mobility $^{a}$ & -- & & $4^{\mathrm{d}}$ & (33.3) & -- & \\
\hline Visual impairment $^{\mathrm{b}}$ & -- & & 2 & $(16.7)$ & -- & \\
\hline Cognitive $^{c}$ & -- & & 2 & $(16.7)$ & -- & \\
\hline $\begin{array}{l}\text { Number of overlapping } \\
\text { disabilities }\end{array}$ & -- & & $6^{\mathrm{e}}$ & $(50.0)$ & -- & \\
\hline $\begin{array}{l}\text { Median years since diagnosis } \\
\text { of disability }\end{array}$ & -- & & $\begin{array}{c}13.5 \\
\text { (range } \\
1-35)\end{array}$ & & -- & \\
\hline
\end{tabular}

${ }^{a}$ All students with a mobility-related disability also had another disability. ${ }^{b}$ One student with visual impairment

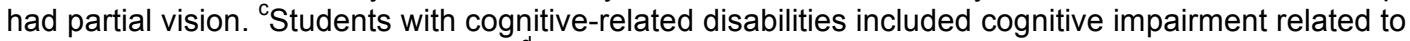
congenital or autoimmune disorders. ${ }^{\mathrm{d}}$ All were in combination with another disability of which students felt their other disability (other than mobility related) was more significant). ${ }^{\circ}$ One student had LD and anxiety but was categorized as LD, since that was the student's major disability. One student with LD and one with cognitive disability had mobility issues/disabilities. Two students with psychiatric disabilities also had mobility-related disabilities of which the students felt were more secondary to their psychiatric disabilities. One student with visual impairment also was diagnosed with LD; however, the student felt this was more secondary than her visual impairment and thus categorized as such.

\section{Accommodation Issues}

Most students with disabilities were satisfied with the accommodations received and thought they were adequate $(\mathrm{n}=9)$. Students, however, noted concerns with regards to staff and faculty, including their need for more training and their lack of awareness in working with students with disabilities. Another issue noted was that some accommodations were not appropriately executed by staff. One student with a psychiatric disability stated that for a testing accommodation, staff wanted to have all the students start taking the exam at the same time but did not allow the amount of time students were supposed to have for the exam. Some students also found that it was difficult with their 
disability to take adequate notes. An accommodation for this was note takers. Students with disabilities also did not want to be a burden, and thus, would not pursue some accommodations or prefer some rather than others. One student stated that using human readers made him uncomfortable, adding extra distraction during examination.

The theme of how long it takes students with disabilities to study and complete assignments or readings was discussed. A student with visual impairment and LD stated, "I'm here extra hours early just to give myself time to process the information." Another theme was related to wanting independence. One student with a visual impairment reported having a poor experience conducting research at the university library and having to rely on accommodations, such as library staff assistance. The student, having been at the IHE at least two years, noted, "The library ... I feel that I don't get a good experience when researching ... because I'm depending on somebody else. They say you have to come with a title, the article number. I don't have that stuff." Students commented that experiences like these limit independence and raises barriers.

Another issue with accommodations is that they may not be functionally appropriate. For example, a student with a cognitive and fine-motor impairment noted problems with a voice recognition accommodation. This accommodation was intended to help him use the computer as a way of bypassing his fine motor problems. However, he also had a speech impediment and was unable to complete the training because the voice recognition software would often not recognize his commands. This raises the issue of appropriate assessment for support or lack of follow-up in how accommodations and assistive products are benefiting the student.

\section{Learning Preferences}

Common themes for students included making connections between the material presented in class, actually understanding the material, being able to demonstrate their knowledge, and preferring UDL/UDI principles. This was most frequently discussed among students with cognitive disabilities and LD $(n=6)$. One student with LD explained, "It's just that I process information differently than other people." Some students with LD and cognitive disability noted that learning with words can be difficult to grasp. The highest-rated learning preference was having the opportunity to try things hands-on, and practice or demonstrate what was learned (see Table 3). These related to the UDL principle of expression, where learning by doing allows students to express themselves in alternate ways. This allows students the UDI principle of tolerance for error, where students can practice lessons, and learn from feedback and trial and error.

Table 3 shows that a consistent theme was that students learned best through a combination of learning preferences. Since students vary in their learning preferences, the curriculum needs to provide flexibility to match these various preferences. There was agreement among students that learning and achievement are aided by professors using a variety of instruction methods based on UDL/UDI and by students using a variety of learning tools. 
Table 3

Median Ratings of Learning Preferences

\begin{tabular}{lccc}
\hline & $\begin{array}{c}\text { All } \\
\mathbf{n = 1 5}\end{array}$ & $\begin{array}{c}\text { With Disability } \\
\mathbf{n = 1 2}\end{array}$ & $\begin{array}{c}\text { No Disability } \\
\mathbf{n = 3}\end{array}$ \\
\hline Orally & 3.0 & 2.5 & 3.0 \\
Visually & 3.0 & 3.0 & 3.0 \\
Hands-on & 3.0 & 3.0 & 3.0 \\
Explained with words & 2.0 & 2.0 & 3.0 \\
Pictures, graphs, charts & 3.0 & 3.0 & 3.0 \\
Draw for yourself & 2.0 & 2.0 & 2.0 \\
Practice or demonstrate & 3.0 & 3.0 & 3.0 \\
\hline \multicolumn{2}{c}{ Note: Likert scale 1.0 through 3.0, where 1.0 is not useful/important, and 3.0 very useful/important. }
\end{tabular}

\section{UDL and UDI Principles}

The perspectives of students both with and without disabilities were categorized based on the principles of UDI and UDL (see Table 4).

Equitable use. Questions that pertained to equitable use asked students about note takers or sharing class notes, copy of class notes or lecture slides before class, and recording lectures. Other questions asked students about various instructional methods and activities in class, and about accessing class materials. All students gave a high rating to you have access to the same class materials that other students have, indicating that all students want to be on an equal playing field.

Having a copy of lecture notes, note takers, or sharing class notes was especially useful for providing equity in use for students who have difficulty writing or trouble seeing the board or slides during class. This was also important in demonstrating student perception of the UDL principle of multiple means of representation. It allows options for comprehension. A student with a psychiatric disability noted that having the class lecture slides ahead of time was important: "I can listen to him teach rather than trying to copy the PowerPoint down on note paper, and this made me have time to listen." Regarding recording class lectures as a method of taking notes, many students stated that this helped them focus more on lectures and processing the material as compared to writing down everything the professor stated. Through this, students noted that they can stay more engaged and it helps them have another form of class material to refer back to when needed. 
Table 4

Median Ratings of Questions related to $U D L / U D I$

\begin{tabular}{|c|c|c|c|}
\hline & $\begin{array}{c}\text { All } \\
n=15\end{array}$ & $\begin{array}{c}\text { With Disability } \\
n=12\end{array}$ & $\begin{array}{c}\text { No Disability } \\
\qquad n=3\end{array}$ \\
\hline \multicolumn{4}{|l|}{ Learning Tools } \\
\hline Note takers/sharing notes & 2.0 & 3.0 & 2.0 \\
\hline Adaptive technology & 3.0 & 3.0 & not used \\
\hline Moving location in class & 3.0 & 3.0 & 1.0 \\
\hline Tutors & 3.0 & 3.0 & 2.5 \\
\hline Alternate format textbooks (e-books) & 3.0 & 2.0 & 1.0 \\
\hline $\begin{array}{l}\text { Tape or digital recorder } \\
\text { Copy class notes/lecture slides ahead }\end{array}$ & 3.0 & 3.0 & 3.0 \\
\hline of class & 3.0 & 3.0 & 3.0 \\
\hline Counseling services & 3.0 & 3.0 & 3.0 \\
\hline Writing lab & 3.0 & 3.0 & 3.0 \\
\hline \multicolumn{4}{|l|}{ Instructional Methods } \\
\hline Lecture & 2.0 & 2.0 & 2.0 \\
\hline Guest speaker & 3.0 & 3.0 & 2.0 \\
\hline Brainstorming & 3.0 & 3.0 & 3.0 \\
\hline Videos & 2.0 & 2.0 & 3.0 \\
\hline Class discussion & 3.0 & 3.0 & 2.0 \\
\hline Small group discussion & 3.0 & 3.0 & 2.0 \\
\hline Case studies & 3.0 & 2.5 & 3.0 \\
\hline Hands-on or interactive activities & 3.0 & 3.0 & 3.0 \\
\hline Critical thinking & 3.0 & 3.0 & 3.0 \\
\hline Access same materials & 3.0 & 3.0 & 3.0 \\
\hline Choice in assessment & 3.0 & 3.0 & 3.0 \\
\hline Clear expectations & 3.0 & 3.0 & 3.0 \\
\hline $\begin{array}{l}\text { Turn in individual components for } \\
\text { feedback for later integration }\end{array}$ & 3.0 & 3.0 & 3.0 \\
\hline Outline prior class & 3.0 & 3.0 & 3.0 \\
\hline Classroom arrangement & 3.0 & 3.0 & 3.0 \\
\hline Receive feedback & 3.0 & 3.0 & 3.0 \\
\hline Communication with fellow students & 3.0 & 3.0 & 3.0 \\
\hline Professor approachable & 3.0 & 3.0 & 3.0 \\
\hline Same expectations for all students & 3.0 & 3.0 & 3.0 \\
\hline
\end{tabular}

Flexibility in use. Interview questions regarding the UDI principle of flexibility in use were those pertaining to the instructional methods professors used. These questions related to the UDL principles of representation, guidelines 1.1 and 2.3; expression, guideline 5.2; and engagement, guidelines 8.2 and 8.3. Most instructional methods were rated high, with the exception of lectures and videos, which were rated lower. The lower rating may be related to engagement, since a few students actually noted that videos can have more limited engagement compared to other instructional methods. One student 
with a cognitive disability stated, "Videos are useful to an extent. Videos can be very informational or junk and sometimes they make you fall asleep." Two of the highestrated instructional methods were class and small-group discussion. Discussions provide students another way of experiencing knowledge. It also provides engagement by fostering collaboration and another option for expression and communication. A student stated, "Discussions help to understand or get those points you didn't catch."

Simple and intuitive. For the UDI principle of simple and intuitive, students answered a question on the importance of having written and straightforward course expectations. This question relates to engagement as it helps students self-regulate and optimize motivation, an engagement factor of UDL. Students noted that knowing what to expect through clear goals and objectives for the class allowed them to properly manage their time and obtain desired grades. One student noted that although having clear expectations is important, some professors did not always make those expectations evident, making learning and preparation for class difficult.

Perceptible information. Questions asking students about the learning tools of alternative media books (e.g., e-books) and having class outline or lecture slides ahead of time represents the UDI principle of perceptible information and the UDL principles of expression and representation. Students highly rated the usefulness of receiving class outlines ahead of time, since it helped them stay focused and "keep up" in class. Alternative media textbooks were more useful for some students, depending on their learning preferences and disabilities. Students with visual impairment gave a high rating to alternative media textbooks, and other students rated them as sometimes useful. Students noted the reason for lower ratings was that it is more difficult to be interactive with some alternative media. With a hard-copy text, they can highlight and underline, which helps with understanding and comprehension of the information. This relates to the UDL principle of representation.

Tolerance for error. To obtain their perspectives on the UDI principle of tolerance for error, students were asked about the usefulness of writing labs and having the option to turn in project components for feedback prior to integration into a final paper/project. These questions relate to UDL principles of engagement, expression, and representation. Writing labs were highly rated. They allow students to practice and improve their writing through feedback. Similarly, allowing students to turn in project components for feedback was highly rated. This method allows students at various skill levels to move at their own pace and builds on the expression principle, since it supports planning and strategy for learning, in which the professor helps guide students through feedback. This method also uses graduated levels of support to build confidence and skills of students, as this helps them with practice. One student with a psychiatric disability stated, "I need constant feedback ... so I know which direction I'm going or if there's things that need to be modified. And I learn better that way."

Low physical effort. Questions related to the UDI principle of low physical effort include those asking about adaptive technology and about allowing students to choose how they will be evaluated. These questions pertain to the UDL principles of expression and engagement. Use of technology such as a screen reader and a computer to take an exam aids students who would otherwise have difficulty, as represented by student 
statements. Also, using a computer to take an exam assists those with difficulty writing by hand and improves concentration for others. A student with a psychiatric disability noted that when completing exams on a computer, "It was very useful, seemed like I go faster and was more organized ... it helped me think clearer so I wouldn't stress out about looking at all the questions that you had to answer if it was on paper."

The ability for students to choose how they will be evaluated was highly rated. Nearly all students noted this helps them demonstrate what they know. A student with LD expressed, 'I'm not a great test taker, and there are certain other avenues where I shine. And it would give you a fair advantage to demonstrate the information you learn if it's in a different method.... It would make the professor realize, oh, they [students] got it." This relates to the UDL principle of expression, in which students are provided multiple means for communication and expression. This also relates to engagement because it allows for individual choice and autonomy.

Size and space for approach and use. The UDI principle of size and space for approach and use refers to instruction. The interview questions pertaining to this principle include moving to a different location of the classroom and arranging the classroom for accessibility. These questions helped elicit perceptions of the UDL principle of engagement. Overall, students with disabilities gave a high rating to moving to a different location in class, whereas students without disabilities rated this lower. Students with disabilities noted that this helps them pay attention in class and to stay engaged and focused with fewer distractions.

For the questions regarding the importance of an accessibly arranged classroom, the rating was high. Both students with and without disabilities understood the importance of this concept. It helped students focus and stay engaged when they did not have to be concerned about barriers or space issues. One student noted that being very physically close to other students was uncomfortable and distracting, especially with overcrowded classrooms. Another student without a disability stated, "I'd say the organization of the class is very important because if you got chaos everywhere then it's hard to learn." This suggests that the arrangement of a classroom should match the number and size of students to encourage maximal learning.

A community of learners. Questions in this study that represented the UDI principle of a community of learners were use of tutors, counseling services, class and small-group discussions, and communication and interaction among fellow students. These questions also related to the UDL principle of engagement. Usefulness of tutors and counselors were rated highly. One student with a visual impairment stated, "They were able to make me see what I couldn't see from the book or in class." Many students used counseling services and found these extremely beneficial, especially with the stress and pressures related to university life. Tutoring and counseling helps students develop personal coping skills. This relates to the UDL principle of engagement. Students are also able to reflect and make assessments on the next steps needed to ensure their success in learning.

The final questions involved class and small-group discussions and interaction or communication among students. Overall, these questions were rated high on the Likert scale. Discussions help students gauge their level of learning and understanding of class 
material. It also helps them learn the material when they hear another student's interpretation of the material. One student with LD stated, "It's helpful because you get a lot of points of view and ... someone else could give you the understanding and get the key notes." A student without a disability stated, "Sometimes it's good to get feedback from other students because it can increase your understanding of the concept that is being taught."

Instructional climate. Questions pertaining to the UDI principle of instructional climate related to comfort in discussing issues or accommodations with a professor, having a professor who is approachable, available and has high expectations for all students. These questions also related to the UDL principles of expression, guideline 6.1, and engagement, guideline 7.3. Students' ratings for these questions were consistently high. Most students were comfortable speaking with professors about accommodations, class assignments, grades, and other issues. This related to fostering a positive instructional climate and promoting engagement. A few students stated they were uncomfortable, related more to their concerns for stigma related to the type of disability they have, which are hidden disabilities. Some professors may unintentionally discuss accommodations while classmates are present, about which one student with LD stated, "I know they don't mean to do it, but it just points you out."

Professors who are approachable help create an inclusive environment that is conducive to learning. For the question on professors having the same expectations for all students, every student rated this as highly important. A student with LD and a visual impairment stated, "I definitely want a high standard, and I want to be seen as an intelligent person who is able to do things." Another student with LD stated, "I want to make sure I can pair up against anyone." A student with a cognitive and mobility disability noted, "It's important because if there were lower expectations, then me in that classroom does not mean a thing... If I am expected to perform at a lower level, then that does not validate a person with a disability. It validates the disability."

\section{Discussion}

Findings related to the characteristics of the students with disabilities were revealing. The students with disabilities were slightly older than students without disabilities. The majority of students with disabilities were at the undergraduate level even though they were older, which is consistent with the literature (Horn \& Malizio, 2002; National Center for Education Statistics, 2009). Half the students with disabilities had more than one disability. Since students with multiple disabilities can present additional challenges for educators, instruction needs to be usable by this broad range of students. Applying the UDL/UDI principles will help alleviate some accommodations that may be inappropriate, and will create a more inclusive learning environment.

\section{Themes}

Issues that students with disabilities raised relate to accommodations and the process of providing accommodations. Students expressed concerns and indicated the existence of barriers related to their accommodations or the receipt of inappropriate accommodations, which can cause distraction for students. An important perspective 
revealed in this study involves the stigma of disability and disclosure of information. Students with hidden disabilities (LD and psychiatric disability) expressed discomfort in discussing accommodations or disclosing their disabilities with professors. For students with physical or sensory disabilities, choosing not to disclose is not an option for them. This stigma and fear of invoking negative reactions and related concerns of disclosure have been discussed in the literature (Claiborne, Cornforth, Gibson, \& Smith, 2010; Marshak et al., 2010).

It has been noted in the literature that accommodations should match a student's functional needs (Burgstahler, 2007; Kurth \& Mellard, 2006). In the present study, some accommodations described did not functionally match the needs of some students. UDL/UDI, on the other hand, considers their needs and builds many accommodations into the design of the curriculum and instructional materials inclusive of all students, regardless of disability (McGuire et al., 2003; Silver, Bourke, \& Strehorn, 1998). This would eliminate this concern students expressed, and their focus could be on learning.

Learning preferences among students varied. Some preferences were rated higher or lower depending on the student and disability. All students expressed that they learned best with a variety or combination of preferences.

\section{UDL and UDI}

UDL generally has been studied in the $\mathrm{K}-12$ setting. This study provided evidence in support of UDI and UDL principles through student perspectives, and for potential application of UDL principles in the higher education setting. With UDL/UDI, students would be allowed various means to comprehend class material; they would be able to stay focused and engaged without needing to worry about barriers or space issues that would obstruct learning. Since students gave a high rating to receiving slides or notes for the class or lecture ahead of time, allowing them to prepare for class, in designing curriculum with UDL/UDI principles, professors can make these materials available for students to access. This also may help students have increased engagement during class, and decrease the need to write extensive notes. Students with visual impairment mentioned that a screen reader is preferable to relying on a human reader for exams. Had examinations been designed with UDL/UDI principles, such as with accessibility built-in (e.g., allowing the use of a computer and/or screen reader to take the exam), then it would fulfill the principles of equity and flexibility in use for UDI and the principle of expression for UDL.

Providing a diversity of interactive activities through a community of learners, such as class and small-group discussion, encourages learning and increases motivation. Fostering open communication and a positive instructional climate using these UDL and UDI principles has the potential to help students with disabilities to be motivated in learning and, possibly, to diminish the insecurities they may have about their disabilities, particularly if there is stigma associated with the disability. Setting high expectations for all students is also important for UDL/UDI. Having professors set different or lower expectations for students with disabilities is not in line with either the UDI principle of instructional climate or the UDL principle of engagement (CAST, 2013b; McGuire \& Scott, 2006a). This would not promote motivation to perform well and optimize learning, 
and students would not be challenged, which would limit achievement. Having a variety of methods is more inclusive of all students.

UDL/UDI is not limited just to the classroom and instruction, but also extends to other areas and services that relate to student education. An example given by a student was the library service that required the student to have several pieces of information for a reference without actually offering a service whereby the student can conduct his or her own research. This keeps students with disabilities from being independent and raises barriers to learning and education. This library process was difficult for a student who had been at the IHE for some time; it would be especially difficult for students just starting their studies. These accommodations from the library are also limited, since students noted they depend on library personnel who are only available during certain days and times. UDL/UDI is important for curriculum design and other components of higher education, including library procedures and policies and those of other learning laboratories that students require during their education. Designing a library with UDL/UDI principles, making websites more usable and accessible, and converting printonly items to alternate format - such as rich text format or other forms of electronic text-based on the student's need are examples that allow students to be independent without having to depend on accommodations.

\section{Limitations and Future Research}

A limitation of this study was that it included no students who were Deaf or hard-ofhearing. Another limitation of this study was that it was conducted at a single IHE and used a qualitative study design; therefore, the findings cannot be readily generalized to other institutions and all students with disabilities. The sample size was small; however, it was an exploratory study. The study might have been improved if more students had been interviewed. Also, only one method of data collection was used for this study. It also may have been useful to triangulate some of the results from the interviews with documents from their classes, such as their syllabi, handouts, and lecture materials.

Future research might survey a larger sample of students with and without disabilities to determine if the perspectives found in this study also apply in a larger population. Other future research might explore the effectiveness of applying UDL/UDI principles to services and programs in higher education other than classroom instruction.

\section{Implications for Practice}

This study suggests the importance of raising awareness and improving training and education in IHEs targeted at increasing familiarity in meeting the needs of students with disabilities through UDL/UDI. One approach to improve practice in this area, in addition to education and training, is establishing mentorship programs to build awareness and increase familiarity for faculty in relation to working with students with disabilities. An example of a successful implementation of such a program occurred at Ball State University (Harris, Ho, Markle, \& Wessel, 2011). The program promoted collaboration between faculty and the disability service office. Furthermore, educating students on selfadvocacy and self-awareness was recommended. There were students in the study described in this paper who were unaware of the accommodations available to them and 
their rights. Raising self-awareness in this area can be done through a general university orientation for all incoming students and additional training for students with disabilities, which includes self-advocacy skills. Focusing on the higher education community promotes values that are conducive to a more inclusive and just environment where students are treated fairly and without barriers (Armstrong, 2012).

Another important understanding from this study is that when faculty members used approaches that followed UDL and UDI principles, students expressed these were conducive to their learning, since it allowed them to succeed in higher education. These approaches are: establishing clear expectations, providing advanced organizers, presenting information in multiple formats, giving frequent informative feedback, and using diverse assessment strategies. This is comparable to the findings by Madaus, Scott, and McGuire (2003b), who found that the most effective teaching methods were similar to principles of UDL. It is important to ensure that accommodations match the students' functional needs when building accommodations into curricula based on UDL/UDI principles. A three-way collaboration should be established among students, disability support staff, and faculty when designing curricula. Many of these strategies can be included in educating faculty and staff. Training can be in the form of workshops or a "Universal Design Skills Day."

Curriculum using UDL/UDI principles should be flexible and allow students to learn course content in different ways based on their differing needs and learning preferences. This type of UDL/UDI curriculum would provide students with disabilities effective, equitable, and nondiscriminatory learning environments that enhance positive student achievement, alleviating the burden of requesting accommodations. It may be useful to incorporate UDL/UDI principles on a wide scale in higher education curricula, support services, and programs that students with disabilities may use to improve accessibility.

Since implementing UDL/UDI may require a system-wide approach, this can be done in phases, as represented by the model proposed by Edyburn (2010). There are three phases for meeting the needs of students with disabilities: advocacy, accommodation, and accessibility. Currently, many institutions are in the accommodation phase. To get to the accessibility phase, Edyburn recommended that UDL must be integrated into the field of instruction, where instructional practices taught to future educators should be based on UDL principles at the pre-service level, meaning considering UDL principles during development of curriculum and programs. Not including this is a major problem limiting the potential of UDL. This can be accomplished by policies and guidelines that provide "roadmaps" for faculty and staff on how to ensure access to electronic and information technologies for students with disabilities (Harbour, 2010). These efforts in designing curricula and the educational environment need to be continued and improved.

\section{Conclusion}

The important contributions of this study include support for the findings in the literature, evidence for UDL and UDI through the perspectives of students, and additional evidence for support of UDL in higher education, which has not been traditionally used in this setting. Implementing UDL/UDI principles may help reduce learning barriers for 
students of all abilities, and allow students with disabilities to succeed on an equitable basis in higher education. Ultimately, this may benefit all students.

\section{References}

Americans with Disabilities Act of 1990, 42 U.S.C.A. § 12101 et seq. (1990).

Armstrong, F. (2012). Landscapes, spatial justice and learning communities. International Journal of Inclusive Education, 16(5-6), 609-626. doi: 10.1080/13603116.2012.655496

Ashman, A. (2010). Modelling inclusive practices in postgraduate tertiary education courses. International Journal of Inclusive Education, 14(7), 667-680. doi:10.1080/13603111003778429

Bevan, N. (1995). Measuring usability as quality of use. Software Quality Journal, 4(2), 115-130. doi: 10.1007/BF00402715

Block, L. S., Loewen, G., \& Kroeger, S. (2006). Acknowledging and transforming disabling environments in higher education: AHEAD's role. Journal of Postsecondary Education and Disability, 19(2), 117-123. doi: http://www.ahead.org/jped/

Burgstahler, S. (2007). Who needs an accessible classroom? Academe, 93(3), 37-39.

Burgstahler, S. (2012). Universal design: Process, principles, and applications. DO-IT (Disabilities, Opportunities, Internetworking, and Technology). http://www.washington.edu/doit/Brochures /PDF/ud.pdf

Burgstahler, S., \& Moore, E. (2009). Making student services welcoming and accessible through accommodations and universal design. Journal of Postsecondary Education and Disability, 21(3), 155-174. http://www.ahead.org/publications/jped

CAST. (2013a). Research and development. http://www.cast.org/research/index.html

CAST. (2013b). UDL guidelines version 2.0. http://www.cast.org/udl/index.html

Center for Universal Design. (1997). The principles of universal design, version 2.0. Raleigh, NC: North Carolina State University.

Center for Universal Design. (2008). Universal design principles. http://www.ncsu.edu /www/ncsu/design/sod5/cud/about_ud/udprinciples.htm

Claiborne, L. B., Cornforth, S., Gibson, A., \& Smith, A. (2010). Supporting students with impairments in higher education: Social inclusion or cold comfort? International Journal of Inclusive Education, 15(5), 513-527. doi: 10.1080/13603110903131747

Cohen, R. J., \& Swerdlik, M. E. (2005). Psychological testing and assessment: An introduction to tests and measurement (6th ed.). Boston, MA: McGraw-Hill.

Creswell, J. W. (2012). Qualitative inquiry and research design: Choosing among five approaches (3rd ed.). Thousand Oaks, CA: Sage.

Edyburn, D. L. (2010). Would you recognize universal design for learning if you saw it? Ten propositions for new direction for the second decade of UDL. Learning Disability Quarterly, 33(1), 33-41. doi: 10.1177/073194871003300103

Embry, P. B., Parker, D. R., McGuire, J. M., \& Scott, S. S. (2005). Postsecondary disability service providers' perceptions about implementing universal design for instruction (UDI). Journal of Postsecondary Education and Disability, 18(1), 34-48. http://www.ahead.org/publications/jped

Harbour, W. S. (2010). Universal design for transition: A roadmap for planning and instruction. Intellectual \& Developmental Disabilities, 48(4), 303-304. doi: 10.1352/1934-9556-48.4.303 
Harris, J., Ho, T., Markle, L., \& Wessel, R. (2011). Ball State University's faculty mentorship program: Enhancing the first-year experience for students with disabilities. About Campus, 16(2), 27-29. doi: http://dx.doi.org/10.1002/abc.20058

Hehir, T. (2005). New directions in special education: Eliminating ableism in policy and practice. Cambridge, MA: Harvard Education Press.

Horn, S., \& Malizio, A. (2002). Profile of undergraduates in U.S. postsecondary education institutions: 1999-2000: Statistical analysis report (NCES 2002-168). U. S. Department of Education. Washington, DC: National Center for Education Statistics.

Izzo, M. V., Murray, A., \& Novak, J. (2008). The faculty perspective on universal design for learning. Journal of Postsecondary Education and Disability, 21(2), 60-72. http://www.ahead.org/publications/jped

Kurth, N., \& Mellard, D. (2006). Student perceptions of the accommodation process in postsecondary education. Journal of Postsecondary Education and Disability, 19(1), 71-84. http://www.ahead.org/publications/jped

Mace, R. L. (1985). Universal design: Barrier free environments for everyone. Designers West, 33(1), $147-152$.

Madaus, J. W., Scott, S. S., \& McGuire, J. M. (2003a). Addressing student diversity in the classroom: The approaches of outstanding university professors (Tech. Rep. No. 02). Center on Postsecondary Education and Disability, University of Connecticut Retrieved from http://www.facultyware.uconn.edu/files/Tech_Report_02_faculty_interviews.pdf

Madaus, J. W., Scott, S. S., \& McGuire, J. M. (2003b). Barriers and bridges to learning as perceived by postsecondary students with learning disabilities (Tech. Rep. No. 01). University of Connecticut: Center on Postsecondary Education and Disability.

Marshak, L., Van Wieren, T., Ferrell, D. R., Swiss, L., \& Dugan, C. (2010). Exploring barriers to college student use of disability services and accommodations. Journal of Postsecondary Education and Disability, 22, 151-165. http://www.ahead.org/publications/jped

McGuire, J. M., \& Scott, S. S. (2006a). An approach for inclusive college teaching: Universal design for instruction. Learning Disabilities: A Multidisciplinary Journal, 14(1), 21-32. http://www.ldaamerica.org

McGuire, J. M., \& Scott, S. S. (2006b). Universal design for instruction: Extending the universal design paradigm to college instruction. Journal of Postsecondary Education and Disability, 19(2), 124-134. http://www.ahead.org/publications/jped

McGuire, J. M., Scott, S. S., \& Shaw, S. F. (2003). Universal design for instruction: The paradigm, its principles, and products for enhancing instructional access. Journal of Postsecondary Education and Disability, 17(1), 10-20. http://www.ahead.org/publications/jped

McGuire, J. M., Scott, S. S., \& Shaw, S. F. (2006). Universal design and its applications in educational environments. Remedial and Special Education, 27(3), 166-175. doi: 10.1177/07419325060270030501

Mullens, J. E., \& Kasprzyk, D. (1996). Using qualitative methods to validate quantitative survey instruments. Paper presented at the Meeting of the American Statistical Association, Washington, DC.

National Center for Education Statistics. (2009). Number and percentage distribution of students enrolled in postsecondary institutions, by level, disability status, and selected student and characteristics: 2003-04 and 2007-08. Washington, DC: U. S. Department of Education. 
Pliner, S., \& Johnson, J. (2004). Historical, theoretical, and foundational principles of universal instructional design in higher education. Equity \& Excellence in Education, 37(2), 105-113. doi: $10.1080 / 10665680490453913$

Rose, D. H., Harbour, W. S., Johnston, C. S., Daley, S. G., \& Abarbanell, L. (2006). Universal design for learning in postsecondary education: Reflections on principles and their application. Journal of Postsecondary Education and Disability, 19(2), 135-151. http://www.ahead.org/publications/jped

Sapp, W. (2007). Myschooldayonline: Applying universal design principles to the development of a fully accessible online scheduling tool for students with visual impairments. Journal of Visual Impairment \& Blindness, 101(5), 301-307.

Silver, P., Bourke, A., \& Strehorn, K. C. (1998). Universal instruction design in higher education: An approach for inclusion. Equity and Excellence in Education, 31(2), 47-51. doi: $10.1080 / 1066568980310206$

University of Guelph. (2011). Universal instructional design at the University of Guelph, Canada. http://www.tss.uoguelph.ca/uid/index.cfm

\section{Author's Note}

R. David Black, Division of Applied and Advanced Studies in Education, California State University, Los Angeles; Lois A. Weinberg, Division of Special Education and Counseling, California State University, Los Angeles; and Martin G. Brodwin, Division of Special Education and Counseling, California State University, Los Angeles.

Correspondence concerning this article should be addressed to R. David Black, 4351 Fountain Villas Ct., Baldwin Park, CA 91706, U.S.A. Email: dblack3030@gmail.com 


\section{Appendix A: Interview Protocol Questions}

Demographic questions

1. What is your status?

a. Undergraduate

b. Graduate

2. What is your major?

3. What is your age?

4. What is your gender?

Disability information (only for students with disabilities)

5. What is the nature of your disability? (may have more than one)

a. Mobility wheelchair/impairment

b. Learning disability

c. Speech impairment

d. Deaf/Hard of hearing

e. Legally blind/Impaired vision

f. Psychiatric/Emotional

g. Other (please explain)

6. How many years have you had your disability?

7. How do you think your disability affects your functioning in class?

Accommodations satisfaction (only for students with disabilities)

8. How satisfied are you with the accommodations which have been provided to you? Why or why not?

9. How has your experience been when accommodations have been adequate? For example, how does it affect you in class, how does it affect your grades, and so on?

10. How has your experience been when accommodations have been inadequate?

\section{UDI Instructional Climate; UDL Engagement}

11. How comfortable are you in discussion with a professor accommodation (students with disabilities) any issues or needs you may have (illness, lecture clarifications, due date extension, etc.)? If uncomfortable, why? 
Accommodations (only for students with disabilities) and Learning tools as they relate to UDL/UDI

12. Please indicate which accommodations/learning tools you use and how useful is each?

1. Not useful, 2. Sometimes useful, 3. Very useful. Why or why not for each?

Please rate each if used:

a. Note takers/Sharing class notes

UDI equitable use; UDL engagement

b. Extended time on test

[accommodation]

c. Adaptive technology (e.g., screen reader, voice recognition, etc.)

UDI low physical effort; UDL expression; Accommodation

d. Moving to a different location of the classroom

UDI size and space; UDL engagement

e. Tutors

UDI community of learner; UDL engagement, expression

f. Alternative test location [accommodation]

g. Alternative media text books (e.g., e-books, etc.)

UDI perceptible information; UDL representation

h. Captioning - did not asked stud w/o disability, maybe should have [accommodation]

i. Tape or digital recorder

UDI equitable use; UDL expression

j. Sign language interpreter [accommodation]

k. Copy of notes or lecture slides ahead of class

UDI equitable use, perceptible information; UDL expression

1. Human reader

[accommodation] 
m. Counseling services

UDI community of learners; UDL engagement

n. Writing lab

UDI tolerance for error; UDL engagement

o. Please list any accommodations/learning tools that you use that are not listed above.

Learning preferences: UDI equitable use, tolerance for error; UDL representation, expression

13. The next set of questions focus on how you learn best. Please rate each either: 1 . Not useful, 2. Sometimes useful, 3. Very useful. Then tell me why or why not for each.

a. When ideas are presented orally

b. When ideas are presented visually

c. When you have the opportunity to work hands-on, try things out

d. When ideas are explained with words

e. When ideas are explained with pictures, graphs, or charts

f. When you can draw or illustrate things for yourself (for example, drawing a graph)

g. When you can practice or demonstrate what you have learned

h. Other (specify):

Instructional methods and activities to represent UDL/UDI:

UDI equitable use, flexibility in use, community of learners; UDL representation, engagement, expression

14. In your classes, how effective are the following instructional methods? Please rate each as either: 1. Not useful, 2. Sometimes useful, 3. Very useful. Then tell me why or why not for each.
a. Lecture
b. Guest speaker
c. Brainstorming
d. Videos
e. Class discussion
f. Small group discussion
g. Case studies (e.g., vignettes)
h. Hands-on or interactive activities
i. Critical thinking and problem solving activities
j. Others, please list 
Other UDL/UDI principles

15. How important are the following to you in regards to classes you take at school? Please rate each as: 1 . Not important, 2. Sometimes important, 3. Very important. Then tell me why or why not for each.

a. You have access to the same class materials that other students have UDI equitable use; UDL representation

b. You are able to choose how you will be evaluated in (e.g., taking a test, or writing a paper, or having an online project)

UDI low physical effort; UDL expression, engagement

c. Written course expectations are comprehensive, clear and concise (straightforward)

UDI simple intuitive; UDL engagement

d. You have the option to turn in individual project components for feedback for later integration into final project

UDI tolerance for error; UDL engagement

e. Class outline or lecture slides are provided prior to class

UDI equitable use, perceptible information; UDL expression, representation

f. The classroom is arranged so that it is accessible

UDI size and space; UDL engagement

g. You receive feedback from the professor

UDI tolerance for error; UDL expression, representation

h. Communication and interaction among fellow students occurs during the class.

UDI community of learners; UDL engagement

i. The professor is approachable and available.

UDI instructional climate; UDL engagement

j. The professor has the same expectations for me as for other students (but keeps in mind individual circumstances and accommodations)

UDI instructional climate; UDL engagement

16. Please provide any comments you wish to share. 